\title{
A Simplified Approach to Rehabilitation of Swallowing: the Labiotherapy
}

\author{
Patrick Fellus* \\ Président of the French Pediatric Orthodontic Society, University Hospital Robert Debré Paris, France
}

*Corresponding author: Patrick Fellus, Président of the French Pediatric Orthodontic

Society, University Hospital Robert Debré Paris, France.

Received Date: September 19, 2018

Published Date: October 03, 2018

\section{Opinion}

Functional rehabilitation is now part of the treatment of dysmorphoses requiring orthodontic treatment.

But it is actually all practitioners who should be concerned with acquiring a myofunctional balance in the oral zone. Joint prostheses, implants, complete prostheses, periodontal health all these daily acts absorb muscle forces generated by oral praxies.

Abandoned during the initial training, these functional rehabilitation procedures, which are time-consuming and maltreated by the nomenclature, are insufficiently integrated into the daily practice of general practitioners.

The contribution of functional educators [1] to wear all night in addition to a series of exercises, has allowed the gradual integration of this approach in the treatment plans for complete rehabilitation of the masticatory system, without the need the help of speech therapists also facing the difficulty of re-education of swallowing.

Whereas the transition from sucking swallowing to swallowing of the subject type is completely natural and without difficulty for $60 \%$ of children between the age of three and four years with the arrival of chewing in a complete dentition.

"But we found that the maintenance of the intake by sucking in the child maintained a certain delay in the establishment of the praxis of chewing" [2] and the acquisition of the swallowing type subject toothed.

Teats, baby bottles and too soft food do not facilitate the installation of a genetic program that is ours. The innate factors put in place only potentialities: "they will express themselves only if the adequate exogenous conditions intervene in a timely manner" [3].

The practitioner must therefore take care of the withdrawal strategy with the child and his parents to inhibit dysfunctional praxies and be able to facilitate the establishment of physiological praxies. At this age, neuronal maturity does not allow voluntary control of the lingual musculature required for conventional speech therapy, which has led us to consider a more suitable approach to young children: labiotherapy. The control of the labial dynamics is much easier than the control of the lingual dynamics, and it is the starting point of a series of sensory-motor modifications that the works of Eric Kandel and the new data of the neuro sciences to understand:

"Learning leads to a change in the strength of synaptic connections between specific cells of the nervous circuit that convey the behavior".

Learning will consist in tracing new circuits, this plasticity will be done either by remodeling existing programs or by creating new ones. But entrusted to speech therapists or kinesitherapists, even specialized, modification of existing neural circuits will require a modification of neurotransmitters during a dialogue between synapse and nucleus which is always long and tedious.

However a strongly emotional state can bypass normal stresses and create new synapses allowing the direct impression of this experience in long-term memory: if you had a car accident 20 years ago you will always remember that it was raining that day, that you were driving such a car brand and even that you wore such clothes. And yet you have never consciously and regularly repeated this episode [5].

In the same spirit the use of a device preventing the coaptation labial and forcing the child to discover by himself the new mode of swallowing (Froggymouth) has shown its effectiveness and simplicity. The child will be placed 15 minutes a day in front of a television screen that will grab his attention so he will not realize the impossibility of performing the intraoral vacuum and swallow with his usual program. Stress in the brainstem will force him to choose another pattern. The lips not touching any more, it will spontaneously tighten the teeth which will allow the elevation of the posterior part of the tongue against the palatal vault. The 
control of this dynamic will be supported by the trigeminal nerve and will inhibit the action of the facial nerve that controls the labial dynamics. We will thus obtain an almost immediate acquisition of the new praxis (Figure 1-3).

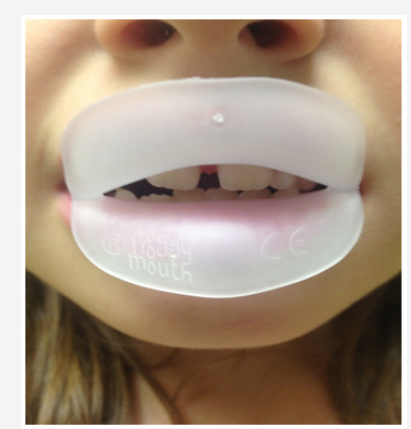

Figure 1: froggymouth prevent a bilabial contact and the sucking deglutition

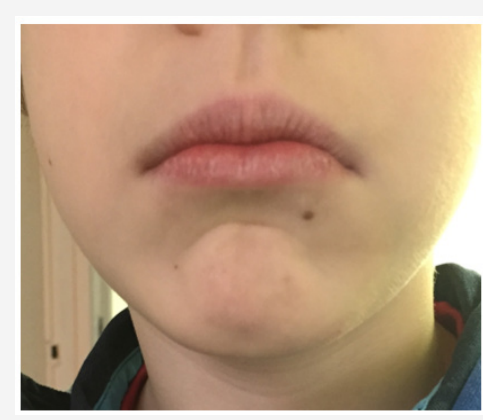

Figure 2 : The icon of suction-swallowing is activated by the facial nerve: "my lips are contracted, my teeth do not touch".

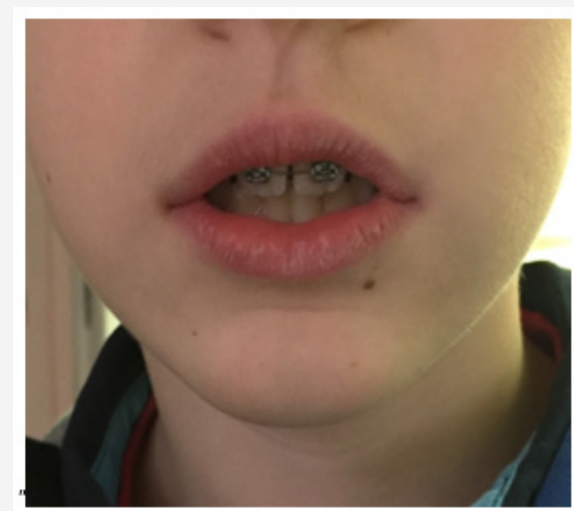

Figure 3: The dented subject swallowing icon: "my lips are relaxed, my molars in occlusion".
The dented subject swallowing icon: "my lips are relaxed, my molars in occlusion" is activated by the trigeminal nerve that will allow not only the molar occlusion but also the protection of the tongue against the bites thanks to the richness of the trigeminal nerve endings of its epithelial cover [6].

The icon of subject-type swallowing: "my lips are relaxed, my molars in occlusion" is activated by the trigeminal that also controls the centers of respiration in the pontic tegmentum by its sensory nucleus will promote a restoration of nasal breathing.

The therapist should therefore monitor the resting posture to relax the perioral musculature and dental occlusion at the time of swallowing. "This double posterior lingual and occlusal functional necessity, too often forgotten by oro-facial rehabilitation therapists, is probably one of the causes of the too frequent failures of reeducation" [7].

As in a game of falling dominoes the simple fact of re-educating the lips ( 2 orbicular) will lead by reorganization of the sensitivomotor areas, a re-education of the 17 muscles of the tongue which will lead to a reeducation of the breathing and a reeducation of the muscles Pharyngeal cycling that will lead to a reeducation of the tympanic musculature. Long underestimated the role of glial cells is now put forward to explain these effects by a bottom-up approach directly targeting the deficit or abnormality, but not requiring the taking awareness of this deficit or anomaly. Intended initially for children receiving orthodontic treatment, the effectiveness of Froggymouth also allows adults to be rehabilitated as long as neurogenesis persists $[8,9]$.

\section{References}

1. Changeux Jean-Pierre (1983) L'homme neuronal Fayard.

2. Couly Gerard (2010) Les oralités humaines Doin.

3. Couly Gerard (2015) Oralité du fotus Sauramps Médical.

4. Fellus Patrick (2003) Orthodontie précoce en dentadura temporal Cdp.

5. Fellus Patrick, Sabouni Waddah, Lalauze-Pol (2016) De la dysfonction à la dysmorphoses Apport de Froggymouth Edición Orthopolis.

6. Froger J, Laffont I, Dupeyron A, Perrey S, Julia M (2017) La plasticité cérébrale Sauramps Medical.

7. Jean Delaire (1996) After Nasal Breathing.

8. Kandel Eric (2011) A la recherche de la mémoire. Odile Jacob.

9. La Recherche, Hors Serie $N^{\circ} 22$ : la mémoire: neurogènes et souvenirs, synapses et protéines, émotions et amygdale. 